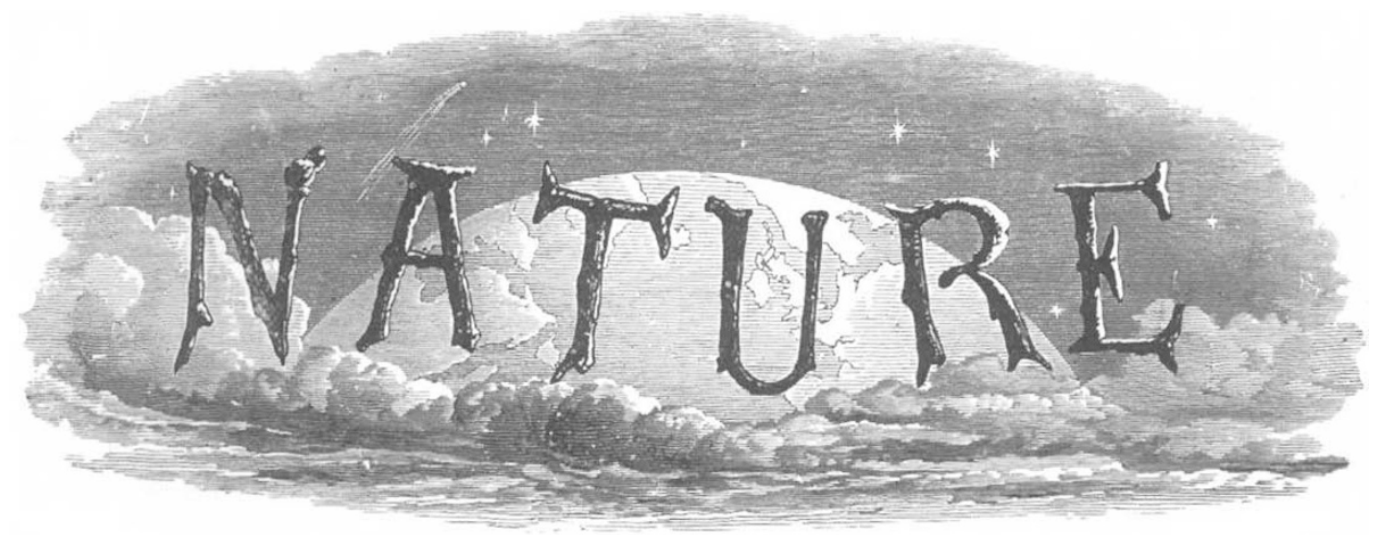

A WEEKLY ILLUSTRATED JOURNAL OF SCIENCE.

"To the solid ground

Of Nature trusts the mind which builds for aye."-WORDsworTH.

THURSDAY, NOVEMBER 7, 1889.

\section{TWENTY YEARS.}

A REMINDER that to-day is the twentieth anniversary of the first issue of NATURE, will not, perhaps, be without interest to our readers, and certainly affords food for reflection to those who in various capacities have been more or less closely connected with this journal from the first.

"When another half-century has passed," said Prof. Huxley in our first number, "curious readers of the back numbers of NATURE will probably look on our best ' not without a smile." "

It will probably be so, but though twenty years is hardly a sufficient interval to make our smiles at our earlier efforts supercilious, it is enough to test whether progress has been made, and whether the forward path is pursued with growing or with waning force.

As regards this journal itself, we may claim that it has not disappointed the hopes of its founders, nor failed in the task it undertook; and we make this claim all the more emphatically because we feel that what has been accomplished has not been due to our own efforts so much as to the unfailing help we have always received from the leaders in all branches of natural science. This help has not been limited to their contributions to our columns, but has consisted also of advice and suggestions which have been freely asked and as freely given. Not the least part of our duty, and even privilege, to-day is to state openly how small our own part has been, and to render grateful thanks to those to whom it is chiefly due that NATURE has a recognized place in the machinery of science, and has secured an audience in all parts of the civilized world.

We do not wish, however, to narrow our retrospect of VoL. XLI.NO. I045. the last twenty years by confining our attention to the measure of success which these pages have won. It has been attained, as we have shown, by the aid of nearly all the best-known scientific writers and workers, not in Britain only but in many countries old and new ; and we cannot believe that they would thus have banded themselves together if evidence had not been given of an honest desire for the good of science and for the "promotion of natural knowledge," or if the attainment of these objects had not been regarded by us as of more importance than a journalistic success. Thus, on its twentieth birthday, we would think not so much of the growth of NATURE as of the advance which in the last twenty years it has chronicled.

A formal history of science for that period would be a formidable task, but it is already possible to discern what will probably appear to posterity to be the most salient characteristics of the last two decades.

In the physical sciences, the enormous development of the atomic theory, and the establishment of a connection between the theories of electricity and light, are perhaps the two main achievements of the years we are considering. Methods of accomplishing the at first sight impossible task of measuring atomic magnitudes have been devised. Our own volumes contain some of the most interesting papers of Sir William Thomson on this subject, and the close agreement in the results attained by very different methods is sufficient proof that, if only approximations, they are approximations we may trust. The brilliant vortex atom theory of Sir William Thomson has not as yet achieved the position of a proved hypothesis, but has stimulated mathematical inquiry. A number of very powerful researches have added to our knowledge of a most difficult branch of mathematics, which may yet furnish the basis of a theory which shall deduce the nature of matter and the phenomena of radiation from a single group of assumptions.

The theory of gases has been extended in both direc- 
tions. The able attempt of Van der Waals to bring both vapour and liquid within the grasp of a single theory is complementary to the extension by Crookes, Hittorf, and Osborne Reynolds of our knowledge of phenomena which are best studied in gases of great tenuity.

The gradual expansion of thermodynamics, and in general of the domain of dynamics from molar to molecular phenomena, has been carried on by Willard Gibbs, J. J. Thomson, and others, until, in many cases, theory seems to have outrun not only our present experimental powers, but almost any conceivable extension which they may hereafter undergo.

The pregnant suggestion of Maxwell that light is an electro-magnetic phenomenon has borne good fruit. Gradually the theory is taking form and shape, and the epoch-making experiments of Hertz, together with the recent work of Lodge, J. J. Thomson, and Glazebrook, furnish a complete proof of its fundamental hypotheses. The great development of the technical applications of electricity has stimulated the public interest in this science, and has necessitated a more detailed study of magnetism and of the laws of periodic currents. The telephone and the microphone have eclipsed the wonders of the telegraph, and furnish new means of wresting fresh secrets from Nature.

Science has become more than ever cosmopolitan, owing chiefly to the imperative necessity for an early agreement as to the values of various units for a common nomenclature, and for simultaneous observations in widely separated localities. International Conferences are the order of the day, and the new units which they have defined are based upon experiments by many firstrate observers in many lands, amongst whom the name $o$ Lord Rayleigh stands second to none.

On the side of chemistry the periodic law of "Mendeleeff has become established as a generalization of the first importance, and the extraordinary feat of foretelling the physical properties of an as yet undiscovered element has attracted to it the attention of the whole scientific world.

The once permanent gases are permanent no more. Dulong and Petit's law has found a complement in the methods of Raoult. The old doctrine of valency is giving way to more elastic hypotheses. The extraordinary progress of organic chemistry, which originated in the work and influence of Liebig and the Giessen school, has continued at an accelerated rate. The practical value of even the most recondite investigations of pure science has again been exemplified by the enormous development of the coal-tar industry, and by the numerous syntheses of organic products which have added to the material resources of the community.

The increase of our knowledge of the sun by means of localized spectroscopic observation; the application of photography to astronomy, and more recently still the extension and generalization of the nebular hypothesis are perhaps the most remarkable developments of those branches of science which relate to astronomy. Stars which no human eye will ever see are now known to us as surely as those which are clearly visible. The efforts to reduce nebulæ, comets, and stars under one common law, as various cases of the collision or aggregation of meteoritic swarms, and the striking investigations of Prof. Darwin on the effects of tidal action, and on the application of the laws of gases to a meteoritic plenum, give promise of a fuller knowledge of the birth and death of worlds.

In the biological sciences, the progress during the last twenty years has consisted chiefly in the firm establishment of the Darwinian doctrine, and the application of it and its subordinate conceptions in a variety of fields of investigation. The progress of experimental physiology has been marked by increasing exactitude in the application of physical methods to the study of the properties of living bodies, but it has not as yet benefited, as have other branches of biology, from the fecundating influence of Darwin's writings: hence there is no very prominent physiological discovery to be recorded. The generation of scientific men which is now coming to middle age has been brought up in familiarity with Mr. Darwin's teaching, and is not affected by anything like hostility or a priori antagonism to such views. The result is seen in the vast number of embryological researches (stimulated by the theory that the development of the individual is an epitome of the development of the race) which these twenty years have produced, and in the daily increasing attention to that study of the organism as 2 living thing definitely related to its conditions which )arwin himself set on foot. The marine laboratories of Naples, Newport, Beaufort, and Plymouth, have come into existence (as in earlier years their forerunners on the coast of France), and served to organize and facilitate the study of living plants and animals. The Challenger and other deep-sea exploring expeditions have sailed forth and returned with their booty, which has been described with a detail and precision unknown in former times. The precise methods of microscopic study by means of section-cutting-due originally to Stricker, of Vienna-have within these twenty years made the study of cell-structure and cell-activity as essential a part of morphology as it had already become of physiology. These, and the frank adoption of the theory of descent, have swept away old ideas of classification and affinities, and have relegated the Ascidian "polyps" of old days to the group of Vertebrata, and the Sporges to the Cœlenterates. The nucleus of the protoplasmic cell - which twenty years ago had fallen from the high position of importance accorded to it by Schwannhas, through the researches of Bütschli, Flemming, and Van Beneden, been reinstated, and is now shown to be the seat of all-important activities in connection with celldivision and the fertilization of the egg. The discovery of 
the phenomena of karyokinesis and their relation to fertilization will be reckoned hereafter as one of the most, if not the most, important of the biological discoveries of the past twenty years.

Apart from Darwinism, the most remarkable development of biological studies during these "twice ten tedious years" is undoubtedly the sudden rise and gigantic progress of our knowledge of the Bacteria. Though the foundations were laid fifty years ago by Schwann and Henle, and great advances were made by Pasteur and by Lister just before our period, yet it is within this span that the microscope and precise methods of culture have been applied to the study of the "vibrions," or "microbes," and the so-called "bacteriology" established. We now know, through the labours of Toussaint, Chauveau, Pasteur, and Koch, of a number of diseases which are definitely caused by Bacteria. We also have learnt from Pasteur how to control the attack of some of these dangerous parasites. Within these twenty years the antiseptic surgery founded by Sir Joseph Lister has received its full measure of trial and confirmation, whilst his opportunities and those of his fellow-countrymen for making further discovery of a like kind have been ignorantly destroyed by an Act of Parliament.

To particularize some of the more striking zoological discoveries which come within our twenty years, we may cite-the Dipnoous fish-like creature Ceratodus of the Queensland rivers, discovered by Krefft; the jumping wheel-animalcule Pedation, of Hudson; the development and the anatomy of the archaic Arthropod Peripatus worked out by Moseley, Balfour, and Sedgwick; the Hydrocorallinæe of Moseley, an entirely new group of compound animals; the fresh-water jelly-fish Limnocodium of the Regent's Park lily-tank; the Silurian scorpion of Gotland and Lanarkshire; the protozoon Chlamydomyxa discovered by Archer in the Irish bogs; the Odontornithes and the Dinocerata of the American palæontologists; the intracellular digestion obtaining in animals higher than Protozoa, and the significance of the "diapedesis" of blood-corpuscles in inflammation, and the general theory of phagocytes due to Mecznikow; the establishment of the principle of degeneration as of equal generality with that of progressive development, by Anton Dohrn; the demonstration by Weismann and others that we have no right to mix our Darwinism with Larmarckism, since no one has been able to bring forward a single case of the transmission of acquired characters. Perhaps the attempt to purify the Darwinian doctrine from Lamarckian assumption will hereafter be regarded-whether it be successful or not-as the most characteristic feature of biological movement at the end of our double decade Its earlier portion was distinguished by the pub'ication of some of Darwin's later works. Its greatest event was his death.
In botany, twenty years ago, the teaching in our Universities was practically sterile. In one of our earliest numbers, Prof. James Stewart defended with some vigour the propriety of intrusting botany to a lecturer at Cambridge who was also charged with the duty of lecturing on electricity and magnetism. It is startling to compare a past, in which botany was regarded as a subject which might be tacked on anywhere, with its present condition, in which there is scarcely a seat of learning in the three kingdoms which is not turning out serious work. The younger English school would be ungrateful if it did not acknowledge its debt to the eminent German teachers from whom it has derived so much in the tradition and method of investigation. Sachs and De Bary have left an indelible mark on our younger Professors. But it would be a mistake to suppose that English modern botany has simply derived from Germany. It has developed a character of its own, in which the indirect influence of Darwin's later work can be not indistinctly traced. There has been a gradual revolt in England, the ultimate consequences of which have still to be developed, against the too physical conception of the phenomena of plant life which has been prevalent on the Continent. Darwin, by his researches on insectivorous plants and plant movements from a purely biological point of view, prepared the way for this; Gardiner followed with a masterly demonstration of the physical continuity of protoplasm in plant tissues. This has thrown a new light on the phenomena studied by Darwin, and we need not, therefore, be surprised that his son, F. Darwin, has started what is virtually a new conception of the process of growth, by showing that its controlling element is to be sought in the living protoplasm of the cell, rather than in the investing cell-wall. On the whole, English botanists have shown a marked disposition to see in the study of protoplas n the real key to the interpretation of the phenomena of plant life. The complete analogy between the processes of secretion in animals and vegetables, established by Gardiner, and the essential part played by ferments in vegetable nutrition, illustrated by Green, are examples of the results of this line of inquiry. To Germany we owe a flood of information as to the function of the cell-nucleus, which it is singular has met with general acceptance but little detailed corroboration in this country.

In morphology a review would be ineffective which did not go somewhat deeply into detail. The splendid hypothesis of Schwendener, of the composite nature of lichens as a commensal union of Algæ and Fungi, has gradually won its way into acceptance. In England there is little of the first rank which calls for note except the researches of Bower on the production of sexual organs on the leafy plant in ferns without the intervention of an intermediate generation.

In vegetable physiology there seems a pause; the 
purely physical line of inquiry, as already suggested, seems to have yielded its utmost. The more biological line of inquiry has only yet begun to yield a foretaste of the results which will undoubtedly ultimately flow from it.

Something must be added as to systematic and geographical botany. The "Genera Plantarum" of Bentham and Hooker, the work of a quarter of a century at Kew, affords a complete review of the higher vegetation of the world, and has been accepted generally as a standard authority. To Bentham also we owe the completion of the "Flora Australiensis," the first complete account of the flora of any great continent.

In geographical botany, perhaps the most interesting results have been the gradual elaboration of a theory as to the distribution of plants in Africa, and the botanical exploration of China, of the vegetable productions of which, twenty years ago, almost nothing was known.

In the classification of the lower plants, perhaps the most interesting result has been the happy observations of Lankester upon a coloured Bacterium, which enabled him to show that many forms previously believed to be distinct might be phases of the same life-history.

In geology probably the greatest advance has been in the application of the microscope to the investigation of rock structure, which has given rise to a really rational petrology. All except the coarser-grained rocks were only capable of being described in vague terms; with modern methods their crystalline constituents are determinable, however minute, and the conditions under which they were formed can be inferred.

It is impossible, even in a brief review of this kind, to think only of what has been won, and to ignore the loss of leaders who were once foremost in the fray. In England three names which will never be forgotten have been removed from the muster-roll. Darwin, Joule, and Maxwell can hardly be at once replaced by successors of equal eminence. As the need arises, however, men will no doubt be found adequate to the emergency, and it is at least satisfactory to know that they will appeal to a public more capable than heretofore of appreciating their efforts.

The support afforded by the Governments of Western Europe to scientific investigation has been markedly increased within the period which we survey. France has largely extended her subsidies to scientific research, whilst Germany has made use of a large part of her increased Imperial revenue to improve the arrangements for similar objects existing in her Universities. The British Government has shown a decided inclination in the same direction: the grant to the Royal Society for the promotion of scientific research has been increased from $-£ 1000$ to $£ 4000$ a year; whilst subsidies have been voted to the Marine Laboratory at Plymouth, to the Committee on Solar Physics, to the Meteorological Council, and quite recently to the University Colleges throughout the country, of which last it is to be hoped that a fair proportion will be devoted to the promotion of research rather than to the reduction of class fees.

Twenty years ago England was in the birth•throes of a national system of primary instruction. This year has seen the State recognition of the necessity of a secondary and essentially a scientific system of education, and the Technical Instruction Act marks an era in the scientific annals of the nation.

The extension of scientific teaching has gone on rapidly within and without our Universities. Twenty years ago the Clarendon Laboratory at Oxford was approaching completion, and was the only laboratory in the country which was specially designed for physical work. Now, not only has Cambridge also its Cavendish Laboratory, but both Universities have rebuilt their chemical laboratories, both have erected buildings devoted to the study of biology, and the instruction of students in both zoology and botany has taken a characteristic practical form which we owe to the system of concentrating attention on a series of selected "types" introduced by Rolleston and by Huxley. Oxford has been furnished with an astronomical observatory by the liberality of Warren De la Rue, and Cambridge has accepted the noble gift of the Newall telescope. Nor have such proofs of the vitality of science been confined to the Universities.

Twenty years ago the Owens College was a unique institution: now, united with two thrivirg Colleges in Leeds and Liverpool, it forms the Victoria University; while science is studied in appropriate buildings in Birmingham, Newcastle, Nottingham, and half a dozen towns beside.

A race is thus springing up which has sufficient knowledge of science to enforce due recognition of its importance, and public opinion can now, far more than in the past, be relied on to support its demands. Fortunately, too, these can be authoritatively expressed. The Royal Society wields, if it chooses to exercise it, an enormous power for good. Admitted on all hands to be the supreme scientific authority in this country, its decisions are accepted with a deference which can spring only from respect for the knowledge and scrupulous fairness by which they are dictated. If sometimes it moves slowly, pur se muove, and it is delightful to turn from the babble of the politicians to the study of an institution which does its work well, and perhaps too noiselessly. But even the House of Commons, hitherto ignorant and therefore apathetic in matters scientific, is awakening to the fact that there are forces to be reckoned with and impulses to be stimulated and controlled which are of more enduring import to the national welfare than mere party politics. And the people, too, are beginning to see that it is to the economic working of these forces, and to the right direction of these impulses, that their representatives are bound to give attention. True it is that 
another generation may possibly pass away before either the House of Commons or even Ministers are sufficiently instructed in science to recognize fully their responsibility in this direction.

Whatever, then, the future may bring, the last twenty years have been characterized by progress both steady and rapid. The tide flows on with no sign of check, and we accept the success of NATURE in no spirit of self-gratulation, but as a straw by which the speed of the current may be gauged.

\section{MODERN VIEWS OF ELECTRICITY.}

Modern Views of Electricity. By Oliver J. Lodge, D.Sc., LL.D , F.R.S. (London: Macmillan and Co., I889.)

$\mathrm{N}$ this interesting book Prof. Lodge gives a very lively $I$ and graphic account of many of the most recent speculations about the nature of electrical phenomena. A work with this object was urgently needed, as the method of regarding these phenomena given in popular treatises on electricity is totally different from that used by those engaged in developing the subject.

The attention called by Faraday and Maxwell to the effects produced by and in the medium separating electrified bodies has had the effect of diverting attention from the condition of the charged bodies in the electric field to that of the medium separating them, and it is perhaps open to question whether this of late years has not been too much the case. To explain the effects observed in the electric field we should require to know the condition not only of the ether, but also of the conductors and insulators present in it; just as a compiete theory of light would include the state of the luminous bodies as well as of the ether transmitting the radiations excited by them. Since matter is more amenable to experiment than the ether, it seem; most probable that we shall first gain an insight into the nature of electricity from a study of those cases where matter seems to play the chief partsuch as in the electric discharge through gases, and the phenomena of electrolysis-rather than from speculations, however interesting, as to what takes place in the ether when it is transmitting electrical vibrations. Prof. Lodge, however, in the work under consideration, devotes most of his space to the consideration of the ether. In his preface he says, "Few things in physical science appear to me more certain than that what has so long been called electricity is a form, or rather a mode, of manifestation of the ether;" and he proceeds to give precision to this somewhat vague statement by developing a theory that electricity is a fluid, and a constituent of a very complex ether. In the first few chapters he supposes that all insulators, including the ether, have a cellular structure the cells being filled with a fluid which is electricity, and which is not able to get from one cell to another unless the walls of the cells are broken down; in conductors, however, there are channels between the cells, so that the electricity is able to flow more or less freely through them. A flow of this fluid is an electric current. But if this is the case, anything which sets the ether in motion will produce an electric current. Now, Fizeau's experiments show that moving bodies carry the ether with them to an extent depending on their index of refraction; so that a disk made of glass or other refracting substance, if set in rapid rotation abont an axis through its centre, and at right angles to its plane, ought to act as if currents were circulating in the disk, and produce a magnetic field around it. In order to avoid the allied difficulty that nothing has ever been observed which indicates that a magnet or a current flowing through a coil possesses gyroscopic properties, Prof. Lodge assumes, in subsequent chapters, that the fluid in the cells of the ether is a mixture of two fluids, and that these two fluids are positive and negative electricity: and that, in order to exhibit any electrical effect, the compound fluid has first to be decomposed into positive and negative electricity by the application of an electromotive force. A current of electricity, on this view, consists of the flow of equal quantities of positive and negative electricity in opposite directions. Thus this, the most " modern view of electricity," is in its most important features almost identical with the old two-fluid theory published by Symmer in 1759. We confess we do not think the theory in its present form advances the science of electricity much : it does not suggest new phenomena, nor does it lend itself readily to explain the action of matter in modifying electrical phenomena; it demands, too, a very artificial ether. It would seem that the first steps required to make a theory of this kind a real advance on the old two-fluid theory would be the discovery of a structure for the ether, which would possess the same kind of properties as the mixture of the two electricities on that theory. A grest deal, too, is left indefinite in the theory: thus, for example, we are not told whether for a given current these streams are moving slowly or with prodigious velocities. In fact, there is throughout the book rather a want of definite conclusions, and this is rather hidden by the vigorous style in which Prof. Lodge writes: he develops his ideas in such an enthusiastic and interesting way that on the first reading they seem to be a good deal more definite than they prove to be on calmer reflection.

But whatever may be thought of Prof. Lodge's theory of electricity, there can be, we think, no two opinions of the value of the numerous models illustrating the properties of electrical systems which he has invented. These must prove of the greatest assistance in enabling the student to gain a clear and vivid idea of electrical processes, and ought to be largely employed by all teachers of electricity.

In a work dealing so briefly with such a multitude of different and difficult subjects it is natural that there should be many statements to which exception might be taken. Prof. Lodge disarms criticism by his frank admission of this ; sometimes, also, by an amusing vagueness of statement: thus, on p. 206 , in speaking of the condition of the ether in icie a strongly-magnetizable substance, he says: "Perhaps it is that the atoms themselves revolve with the electricity; perhaps it is something quite different." There are, however, some statements of a less theoretical kind which seem to us likely to mislead the student. Thus it is stated that the amount of the Peltier effect shows that the difference of potential between zinc and copper is only a few micro-volts. The Peltier effect, however, without further assumption, cannot tell us anything about the absolute magnitude of the difference of 